\title{
Deciding to trust, coming to believe: sentinel lymph node assessment in lung cancer
}

\author{
Yin-Kai Chao \\ Division of Thoracic Surgery, Chang Gung Memorial Hospital, College of Medicine, Chang Gung University, Taoyuan \\ Correspondence to: Yin-Kai Chao. Division of Thoracic and Cardiovascular Surgery, Chang Gung Memorial Hospital at Linkou, Chang Gung \\ University, 5, Fushing Street, Gueishan Shiang, Taoyuan. Email: chaoyk@cgmh.org.tw. \\ Comment on: Digesu CS, Hachey KJ, Gilmore DM, et al. Long-term outcomes after near-infrared sentinel lymph node mapping in non-small cell \\ lung cancer. J Thorac Cardiovasc Surg 2018;155:1280-91.
}

Submitted Aug 28, 2018. Accepted for publication Sep 04, 2018.

doi: $10.21037 /$ jtd.2018.09.15

View this article at: http://dx.doi.org/10.21037/jtd.2018.09.15

The sentinel lymph node (SLN)—defined as the lymph node that first receives lymphatic drainage from a primary tumor-is the most probable site of early micrometastasis. When the SLN is free of metastatic cells, it is unlikely that cancer has spread to any other, more distant nodes. The clinical impact of SLN assessment has been well documented for breast cancer and melanoma $(1,2)$. Specifically, SLN examination in these malignancies has the advantages of (I) allowing less aggressive nodal dissections and (II) promoting a thorough immunohistochemical analysis of nodes with a peculiarly high risk of metastases (3).

Although the SLN assessment has been advocated for performing a less extensive lymphadenectomy in patients with non-small cell lung cancer $(4,5)$, its use is not yet widespread. In this context, non-selective mediastinal lymph node sampling or complete mediastinal lymphadenectomy remains the standard of care in lung cancer surgery.

The low acceptance level of SLN analysis in lung cancer surgery is attributable to several factors. First, differently from axillary lymphadenectomy for breast malignancies, mediastinal lymph node dissection is a relatively safe procedure that carries a low risk of morbidity. Second, SLN identification rates in lung cancer surgery remain suboptimal (4). In general, SLN mapping requires the peritumoral injection of a tracer that subsequently migrates to the node that lies immediately downstream of the neoplasm. To date, several tracers (e.g., colloidal radioisotopes), injection methods, and detection devices have been investigated in an effort to optimize SLN assessment in lung cancer (6-8). However, there are significant issues that may impact SLN detection rates following radioisotope tracer injection (4)—including the high frequency of anthracotic pigmentation in hilar and mediastinal nodes and the presence of the "shine-through" effect $(5,9)$. Recently, the use of near-infrared (NIR) fluorescence imaging for SLN mapping has been proposed to overcome the drawbacks of radioisotope tracers $(10,11)$. Accordingly, injection of indocyanine green (ICG; dose: $>1,000 \mu \mathrm{g}$ ) into the lung via a transpleural peritumoral approach has led to the identification of the SLN in $>90 \%$ of patients (10). Similar high detection rates have been reported using navigational bronchoscopy-guided ICG marking (12). Importantly, a pooled analysis of patients who underwent either endobronchial or transpleural ICG injection suggested that long-term survival outcomes are achievable (13). After a median follow-up of 45 months, patients with a pathologically-negative SLN did not show nodal recurrences or distant metastases-suggesting that the SLN status may accurately reflect the overall nodal stage of patients with resectable non-small cell lung cancer. Conversely, metastatic nodal disease was invariably accompanied by a positive SLN. Taken together, these results indicate that SLN might serve as a marker to tailor the extension of lymph node dissection in this patient group. Encouragingly, patients with pathologically-negative SLN identified with NIR fluorescence imaging showed a better survival than those with negative nodes identified by traditional mediastinal staging. These results lend further support to the hypothesis that intraoperative SLN mapping may help thoracic surgeons optimize resections and enhance patient selection for adjuvant therapy-ultimately improving outcomes in early-stage lung cancer. However, it is noteworthy that the 
SLN mapping protocol implemented by Digesu et al. (13) requires a short time period between ICG injection and NIR visualization. During video-assisted thoracoscopic surgery (VATS), transpleural peritumor injection of ICG was performed 5-10 min before removal of tumors having a mean size of $2 \mathrm{~cm}$ (10). However, it might be difficult to precisely localize small or deeply located target nodules through VATS (14). Consequently, an incorrect ICG injection technique can compromise the accuracy of SLN detection. Because the current clinical scenario is shifting towards an increasing number of small-sized lung malignancies being detected through low-dose computed tomography screening programs (15), we believe that the aforementioned limitation is not negligible. The use of navigation bronchoscopy could be a potential strategy to overcome this issue, but its availability remains limited. We have recently described the use of imageguided video-assisted thoracoscopic surgery (iVATS) for singlestage localization and removal of small pulmonary nodules in a hybrid operating room (16). Compared with traditional preoperative CT-guided localization, this approach led to a significant shortening of the time interval between lesion location and its subsequent removal (17). Furthermore, we have shown the clinical utility of low-dose ICG injections for NIR marking of lung tumors during iVATS (18). We anticipate that the combined use of iVATS and NIR localization may further improve SLN mapping in patients with lung cancer. Albeit being a pilot study involving a limited number of patients, the results by Digesu et al. (13) are encouraging and may pave the way for further clinical investigations on larger samples. We believe that their findings will be invaluable to judge the trustworthiness and clinical relevance of SLN assessment in lung malignancies.

\section{Acknowledgements}

None.

\section{Footnote}

Conflicts of Interest: The author has no conflicts of interest to declare.

\section{References}

1. Lyman GH, Somerfield MR, Bosserman LD, et al. Sentinel Lymph Node Biopsy for Patients With EarlyStage Breast Cancer: American Society of Clinical Oncology Clinical Practice Guideline Update. J Clin
Oncol 2017;35:561-4.

2. Niebling MG, Pleijhuis RG, Bastiaannet E, et al. A systematic review and meta-analyses of sentinel lymph node identification in breast cancer and melanoma, a plea for tracer mapping. Eur J Surg Oncol 2016;42:466-73.

3. Melfi FM, Lucchi M, Davini F, et al. Intraoperative sentinel lymph node mapping in stage I non-small cell lung cancer: detection of micrometastases by polymerase chain reaction. Eur J Cardiothorac Surg 2008;34:181-6.

4. Liptay MJ, D'amico TA, Nwogu C, et al. Intraoperative sentinel node mapping with technitium-99 in lung cancer: results of CALGB 140203 multicenter phase II trial. J Thorac Oncol 2009;4:198-202.

5. Liptay MJ. Sentinel node mapping in lung cancer: the Holy Grail? Ann Thorac Surg 2008;85:S778-9.

6. Liptay MJ, Masters GA, Winchester DJ, et al. Intraoperative radioisotope sentinel lymph node mapping in non-small cell lung cancer. Ann Thorac Surg 2000;70:384-9; discussion 389-90.

7. Nomori H, Horio H, Naruke T, et al. Use of technetium$99 \mathrm{~m}$ tin colloid for sentinel lymph node identification in non-small cell lung cancer. J Thorac Cardiovasc Surg 2002;124:486-92.

8. Kim S, Kim HK, Kang DY, et al. Intra-operative sentinel lymph node identification using a novel receptor-binding agent (technetium-99m neomannosyl human serum albumin, 99mTc-MSA) in stage I non-small cell lung cancer. Eur J Cardiothorac Surg 2010;37:1450-6.

9. Khullar O, Frangioni JV, Grinstaff M, et al. Image-guided sentinel lymph node mapping and nanotechnologybased nodal treatment in lung cancer using invisible nearinfrared fluorescent light. Semin Thorac Cardiovasc Surg 2009;21:309-15.

10. Gilmore DM, Khullar OV, Jaklitsch MT, et al. Identification of metastatic nodal disease in a phase 1 dose-escalation trial of intraoperative sentinel lymph node mapping in non-small cell lung cancer using near-infrared imaging. J Thorac Cardiovasc Surg 2013;146:562-70; discussion 569-70.

11. Yamashita S, Tokuishi K, Anami K, et al. Video-assisted thoracoscopic indocyanine green fluorescence imaging system shows sentinel lymph nodes in non-small-cell lung cancer. J Thorac Cardiovasc Surg 2011;141:141-4.

12. Hachey KJ, Digesu CS, Armstrong KW, et al. A novel technique for tumor localization and targeted lymphatic mapping in early-stage lung cancer. J Thorac Cardiovasc Surg 2017;154:1110-8.

13. Digesu CS, Hachey KJ, Gilmore DM, et al. Long-term 
outcomes after near-infrared sentinel lymph node mapping in non-small cell lung cancer. J Thorac Cardiovasc Surg 2018;155:1280-91.

14. Nakashima S, Watanabe A, Obama T, et al. Need for preoperative computed tomography-guided localization in video-assisted thoracoscopic surgery pulmonary resections of metastatic pulmonary nodules. Ann Thorac Surg 2010;89:212-8.

15. Church TR, Black WC, Aberle DR, et al. Results of initial low-dose computed tomographic screening for lung cancer. N Engl J Med 2013;368:1980-91.

Cite this article as: Chao YK. Deciding to trust, coming to believe: sentinel lymph node assessment in lung cancer. J Thorac Dis 2018;10(Suppl 33):S3978-S3980. doi: 10.21037/ jtd.2018.09.15
16. Hsieh MJ, Fang HY, Lin CC, et al. Single-stage localization and removal of small lung nodules through image-guided video-assisted thoracoscopic surgery. Eur J Cardiothorac Surg 2017. [Epub ahead of print].

17. Chao YK, Pan KT, Wen CT, et al. A comparison of efficacy and safety of preoperative versus intraoperative computed tomography-guided thoracoscopic lung resection. J Thorac Cardiovasc Surg 2018;156:1974-83.e1.

18. Wen CT, Liu YY, Fang HY, et al. Image-guided videoassisted thoracoscopic small lung tumor resection using near-infrared marking. Surg Endosc 2018;32:4673-80. 